\title{
Brief Analysis on Reasons and Solutions of Excessive Neutral-Earth Voltage in Machine Room
}

\author{
Liu Huijuan, Tan yanfeng \\ Beihai Weather Bureau, Guangxi
}

\begin{abstract}
In practical power supply system, voltage always exists between neutral wire and earth wire. Excessive neutral-earth voltage in machine room will not only influence the communication and cause the increase of error rate of data transmission, but also damage network equipment. Some equipment (such as server and minimal machine) is supplied with neutral-earth voltage detection circuit. Once neutral-earth voltage exceeds a certain specified value, the equipment cannot start up. This paper mainly analyzes reasons of excessive neutral-earth voltage in machine room and puts forward corresponding solutions and specific measures.
\end{abstract}

Index Terms - machine room, neutral-earth voltage, excessive, measure

\section{Reasons of Neutral-Earth Voltage}

1. Neutral-earth voltage generated by high-frequency harmonic

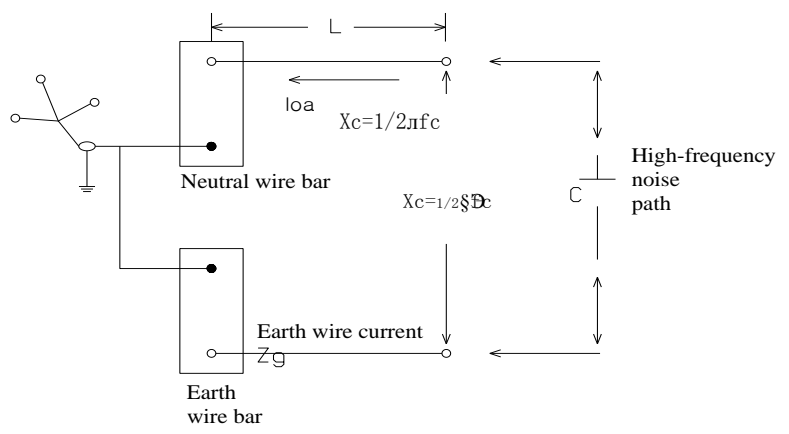

Fig.1 Schematic diagram of neutral-earth voltage generated by high-frequency harmonic

Reactance of neutral wire $Z n=\rho \times L \div S$, where $\rho$ is conductivity of conductor, $L$ is wire length and $S$ is sectional area of conductor ${ }^{[4]}$

If $I n=6 \mathrm{~A}$ and $Z n=0.1 \mathrm{Ohm}, V n$ will be $6 \mathrm{~V}$.

Under high-frequency harmonic, conductors are no longer a pure resistive component, but a mixture integrating inductance, capacitance and resistance, as shown in fig. 2 .



Fig.2 Attribute model diagram of conductors under high-frequency harmonic

Where, inductive reactance is $X_{L}=2 \pi f c$ and capacitive reactance is $X_{c}=1 / 2 \pi f c$ (because coupling inductance and capacitance exist among conductors and higher harmonic will generate certain high-frequency current between neutral wire and earth wire and increase neutral-earth voltage.)

2. Load unbalance during three-phase power distribution:

Machine room shall use TN-C-S method for power distribution according to GB50174 - 93 Electronic Computer Machine Room Design Specification ${ }^{[2]}$. TN-C is used before entering building and TN-S system is used after entering building, as shown in fig.3. If single-phase load is seriously unbalanced, i.e. phase current magnitude is unequal and the included angle is not $120^{\circ}$, the current flowing into center line will be high and the maximum can reach phase current. Due to the existence of impedance of center line, the current in center line will produce potential difference in impedance. Relative to ground potential, points on the neutral wire far away from inlet end might have higher potential.

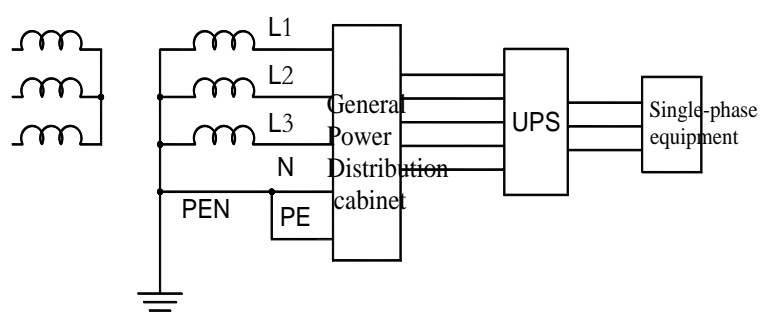

Fig.3 Schematic diagram of three-phase power supply system

3. Non-conformance of ground resistance to specification requirements

In common earthing system, ground resistance of neutral wire and iterative ground resistance of earth wire are required to be less than $4 \mathrm{Ohm}^{[1]}$. Under the condition of excessive ground resistance and poor contact with the earth, 
the potential difference between neutral wire and earth wire might increase under the influence of current generating voltage drop in ground resistance.

\section{Existence of current in PE (earth) wire:}

During normal work, current should not exist in PE wire. However, the following situations might cause the existence of current in PE wire, thus producing voltage drop. Then, the potential difference between neutral wire and earth wire will be different at various points along PE wire.

4.1 Electric leakage of electric equipment, e.g. poor phase line and enclosure insulation, enclosure touch short circuit and reversal phase line and earth wire. At this time, high leakage current passes $\mathrm{PE}$ wire.

4.2 Connection of PE wire and $\mathrm{N}$ wire in a wrong way or short circuit of $\mathrm{PE}$ and $\mathrm{N}$ wire at some point. In the case of hybrid junction of $\mathrm{PE}$ wire and $\mathrm{N}$ wire, stray current is the greatest in PE wire and a part of working current in $\mathrm{N}$ wire will pass PE wire.

4.3 Unequal electric potential at various iterative earth connection points in PE wire. Due to the existence of potential difference, current is generated in PE wire.

4.4 Heavy direct current flows around PE wire (e.g. around subway). Stray current flows into OPE wire through the earth. For example, the traction power of Shanghai subway is $1500 \mathrm{~V}$ DC power and direct current might leak into PE wire through the earth and form stray current.

5. Use of electronic power supply units such as UPS and electronic voltage regulator

UPS has a low power factor and thus has many harmonic components. As mentioned above, harmonic current might cause the increase of neutral-earth potential. In addition, some UPS do not have isolation transformer and cannot effectively restrain neutral-earth potential drift.

6. Non-conformance of earth wire length to requirements

The earth wire of high-frequency electronic equipment is required to be less than $\lambda / 4$ (where $\lambda$ is the length of high-frequency wave); otherwise, standing wave will be generated. As standing wave has wave loop and node (i.e. maximum and minimum voltage), potential difference might exist between both ends of the earth wire.

\section{Solutions for Excessive Neutral-Earth Voltage}

1. All cables in input power distribution cabinet in machine room are subject to heavy current including UPS, lighting on this floor and air conditioning. Each cable contains a lot of electromagnetic interferences. All these cables are bundled up together, making these high-frequency interferences interfere each other. High-frequency interference currents pass neutral wire and earth wire and cause neutral-earth voltage drop. In terms of the test wave, high-frequency components between neutral wire and earth wire are random waves with unfixed frequency. It can also be reflected that the interference is the overlapping of electromagnetic interference of the current of multiple units. The live wire and neutral wire and earth wire of UPS should be separated and their straight-line distance should be more than $20 \mathrm{~cm}$ and better be $40 \mathrm{~cm}$. Other power cables should be same as UPS neutral wire. If they cannot be separated during site construction, neutral wire and earth wire can use armored shielded cable, which can achieve the same effect.

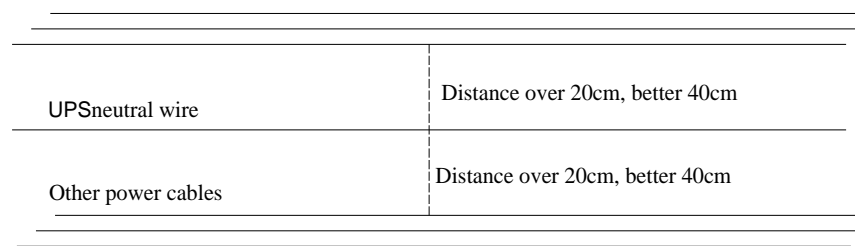

Fig.4 Schematic diagram of increasing distance among conductors and reducing neutral-earth voltage

Advantage of this solution is that no cost will be added and it effectively reduce high-frequency interference through the increase of distance and eliminate the generation of high-frequency current, thus achieving the purpose of reducing neutral-earth voltage. However, its risk is that it could only reduce neutral-earth voltage; with the change of neutral-earth voltage, load or any configuration in the machine room, electromagnetic interference environment might change correspondingly and neutral-earth voltage might drift; thus problems cannot be solved thoroughly.

2. When three-phase load unbalance causes heavy current of neutral wire:

2.1 Adjust the layout of single-phase load and make single-phase load distributed in three phases evenly; meanwhile consider the difference of power factor of electric equipment and make active power and reactive power distributed evenly.

2.2 Conduct iterative earthing for $\mathrm{N}$ wire in load part. Pay attention not to use the same earthing pole as the iterative earthing of PE wire. The iterative earth wire of $\mathrm{N}$ wire and that of PE wire should be insulated without electrical connection. Iterative earthing of $\mathrm{N}$ wire can restrain zero potential drift. The opinion that only iterative earthing of PE wire is allowed in TN-S system is not correct.

2.3 Use power factor compensation device that can adjust unbalanced current. This device uses microcomputer control to adjust three-phase unbalanced current with the method of connecting different quantities of single-phase power capacitor among phases and between each phase and neutral wire, which can compensate for power factor.

2.4 Use the new generation of intellectual UPS product in terms of UPS. Such UPS (e.g. Emerson's Paradigm) has realized real-time monitoring of current in neutral line and can reduce the resultant current of neutral line to zero through real-time matching of three-phase current of rectifier and reduce the increase of output neutral-earth voltage caused by voltage drop of neutral line.

2.5 Add thick neutral wire under the situation of low drift of neutral-earth potential, thus reducing conductor impedance and correspondingly decreasing voltage drop caused by the current in neutral wire ${ }^{[3]}$. 
2.6 Use current-free neutral wire. The line is long, but the expense is considerable.

3. Establish a good earthing system and reduce ground resistance as much as possible. When ground resistance is high, small current will produce neutral-earth voltage. Therefore, it must be reduced. When calculating the diameter of earth wire, after considering the possible maximum electricity consumption of the system and basic requirements of safety, it is necessary to calculate the cable length and specifically specify earth wires of different diameters used on different floors.

4. The following methods can be used to reduce the current in earth wire: strengthen the insulation among phase line, prevent leakage current of equipment from forming loop through earth wire, completely eradicate hybrid junction of neutral wire and earth wire so as to reduce stray current. Each iterative earthing in earth wire cannot be located at different ground potentials. Earth wire should be insulated to earth and subject to single point grounding around the place with heavy DC flow.

5. Choose UPS reasonably. Use the new generation of intellectual UPS product. Such UPS (e.g. Emerson's Paradigm) has realized real-time monitoring of current in neutral line and can reduce the resultant current of neutral line to zero through real-time matching of three-phase current of rectifier and reduce the increase of output neutral-earth voltage caused by voltage drop of neutral line. For large machine room, UPS with high power factor and less harmonic should be used. If the input power factor of UPS is 0.8 and harmonic current is about $30 \%$ during three-phase pulse rectifying, the input power factor of UPS can be 0.95 during three-phase 12 pulse, but it still ahs $10 \%$ harmonic current component. To solve the problem of narrow and small communication machine room, UPS of high-frequency chain structure not containing output isolation transformer has emerged in recent years. However, to isolate neutral wire interference and load, UPS with power frequency isolation transformer should be selected for important load such as large computer network, thus reducing neutral-earth voltage of local electric network while realizing neutral wire isolation. The output zero point of such UPS is the neutral point of secondary $\mathrm{Y}$ winding from isolation transformer. Neutral-earth short circuit at output end and connection of separate lead in $\mathrm{AC}$ working location in the communication machine room to this output point can restrain neutral-earth potential drift.

6. Shortening the length of neutral wire and increasing the sectional area of neutral wire can reduce the reactance of neutral wire and thus reduce neutral-earth voltage.

Advantage of this solution is its apparent effect. According to the computational formula of reactance of neutral wire $Z_{n}=\rho \times L \div S$, when wire length $L$ decreases, the sectional area of conductor increases, $Z_{n}$ decreases correspondingly and neural-earth voltage meanwhile reduces. However, it is not easy to be achieved due to the limitation of practical situation on site. It is necessary to give full consideration in the preliminary design stage of machine room; otherwise, it is difficult to change.

7. Adding isolation transformer is an effective measure for reducing neutral-earth voltage. When neutral-earth voltage is excessive and general methods cannot control it, to ensure normal startup and operation of load, the method of adding isolation transformer can be used to isolate the electrical connection between input and output. However, this method only applies to UPS without built-in isolation transformer. The method of adding output isolation transformer at its output end is generally used.

Advantage of this solution is that it can effectively solve the problem of neutral-earth voltage at load end because neutral wire earthing after isolation can meet various power requirements.

Neutral-earth voltage is an important factor influencing the normal operation of computer. Therefore, solving the problem of neutral-earth voltage in machine room provides guarantee for the normal and stable work of various equipment in machine room.

\section{References}

[1] GB50057-94 Lighting Protection Design Specification of Buildings (2000 Edition).

[2] GB50174-93 Electronic Computer Machine Room Design Specification (2000 Edition).

[3] Yang Yue. Electrical Safety. Beijing: China Machine Press, June 2003.

[4] Wang Zhao'an, Yang Jun, Liu Jinjun. Harmonic Suppression and Reactive Power Compensation. Beijing: China Machine Press, September 1998 . 